\title{
Synthesis and Characterization of Magnetites Obtained from Mechanically and Sonochemically Assissted Co-precipitation and Reverse Co-precipitation Methods
}

\author{
Triastuti Sulistyaningsih, Sri Juari Santosa, Dwi Siswanta, and Bambang Rusdiarso
}

\begin{abstract}
It has been examined the physical and chemical properties of magnetite synthesized mechanically and sonochemically by co-precipitation and reverse co-precipitation methods. Ammonia solution was used as precipitating agent to adjust the $\mathrm{pH}$ of the suspension to reach 11. Characterization of the synthesized magnetites was conducted using the Fourier Transform Infrared Spectroscopy (FTIR), the X-ray diffraction (XRD), Scanning electron microscopy (SEM), and Vibrating Sample Magnetometer (VSM). The characterization results showed that the crystallinity of magnetites synthesized by the ordinary mechanically assisted co-precipitation was higher than that of magnetites synthesized by mechanically assisted reverse-co-precipitation. The involvement of sonochemical treatment instead of mechanical treatment gave smaller and more homogeneous crystal size. The morphology of magnetites was spherical and agglomerated with homogeneous size distribution.
\end{abstract}

Index Terms-Magnetite, mechanically, sonochemically, synthesis.

\section{INTRODUCTION}

Magnetite or ferrous ferrite $\left(\mathrm{FeO}, \mathrm{Fe}_{2} \mathrm{O}_{3}\right.$ or $\left.\mathrm{Fe}_{3} \mathrm{O}_{4}\right)$ is an iron oxide which has an inverse spinel structure with $\mathrm{Fe}(\mathrm{III})$ ions distributed randomly between octahedral and tetrahedral sites, and Fe(II) ions in octahedral sites [1]. Magnetite is highly preferred for many applications such as drug carrier [2], drug release [3], cancer therapy [4], a proton exchange membrane [5] and the heavy metal adsorbent [6]. Main advantage of using magnetic adsorbent is that the magnetic adsorbent is nontoxic and can be reused and easily separated from the solution by an external magnet [7]. Hence, an efficient, economic, scalable and non-toxic synthesis of $\mathrm{Fe}_{3} \mathrm{O}_{4}$ began to grow rapidly.

For most applications of magnetite, require the magnetite nanoparticles to be of uniform size, shape and well dispersed in a solvent. The main factor that affects many interesting properties is the particle size. The size and shape of magnetite particles are generally controlled by synthesis method. There are several techniques that have been used for the synthesis of

Manuscript received June 3, 2015; revised October 26, 2015. This work was supported in part by Directorate General of Higher Education (DGHE), Department of National Education Republic Indonesia for providing the financial support.

T. Sulistyaningsih is with the Department of Chemistry, Faculty of Mathematics and Natural Sciences, Semarang State University, Semarang, Indonesia and Doctoral Program student, Department of Chemistry, Faculty of Mathematics and Natural Sciences, Universitas Gadjah Mada, Yogyakarta Indonesia (e-mail: triastuti.s@gmail.com).

S. J. Santosa, D. Siswanta, and B. Rusdiarso are with the Department of Chemistry, Faculty of Mathematics and Natural Sciences, Universitas Gadjah Mada, Yogyakarta, Indonesia. magnetite, which including co-precipitation of ferrous $\left(\mathrm{Fe}^{2+}\right)$ and ferric $\left(\mathrm{Fe}^{3+}\right)$ ions by an alkali, usually $\mathrm{NaOH}$ solution [8], [9], hydrothermal reaction [10], oxidative co-precipitation [11], reduction reaction with $\alpha$-D-glukose as the reductant [12] and precipitation from partially reduced ferric chlorida aqueous solutions [13].

The co-precipitation process includes several stages : nucleation, growth and secondary process such as agglomeration, attrition, and breakage [14]. The particles obtained with a convention co-precipitation process are relatively larger with a broad size distribution, because it is dificult to avoid the nucleation during the subsequent growth of nuclei [14]. In the other side, sonochemical technology starting developed for peparation of magnetite because the ultrasonic irradiation can decreases the particles sizes of magnetite. In present work, it has been conducted the synthesis of magnetites by mechanically and sonochemically assisted co-precipitation and reverse co-precipitation methods using ammonia solution as precipitating agent and then comparing the results of the synthesis products. The physical and chemical properties of the synthesized magnetites were examined by means of Fourier Transform Infrared Spectroscopy (FTIR), the X-ray diffraction (XRD), Scanning electron microscopy (SEM), and Vibrating Sample Magnetometer (VSM).

\section{PROCEDURE}

\section{A. Reagent}

In this work, all chemicals such as $\mathrm{FeSO}_{4} \cdot 7 \mathrm{H}_{2} \mathrm{O}$, $\mathrm{FeCl}_{3} \cdot 6 \mathrm{H}_{2} \mathrm{O}$ and $\mathrm{NH}_{4} \mathrm{OH}(25 \%$, w/w) were of analytical reagent grade from Merck (Germany) and used without further purification.

\section{B. Synthesis of Magnetite}

$\mathrm{FeCl}_{3} \cdot 6 \mathrm{H}_{2} \mathrm{O}$ and $\mathrm{FeSO}_{4} \cdot 7 \mathrm{H}_{2} \mathrm{O}$ (molar ratio $\mathrm{Fe}^{3+}: \mathrm{Fe}^{2+}=$ 1.5:1) were dissolved in $25 \mathrm{ml}$ distilled water. $\mathrm{A} \mathrm{NH}_{4} \mathrm{OH}(3,5$ M) solution was added dropwise into the mixed $\mathrm{Fe}^{3+} / \mathrm{Fe}^{2+}$ solution at $50^{\circ} \mathrm{C}$ under stirring to increase $\mathrm{pH}$ until 11 . After 3 $\mathrm{h}$ aging, the products were collected by external magnet, washed with distilled water to neutral $\mathrm{pH}$ and then dried at $60^{\circ} \mathrm{C}$ to obtain mechanical magnetite nanoparticles (MMco) [15]. For reverse co-precipitation method, the mixed $\mathrm{FeCl}_{3} \cdot 6 \mathrm{H}_{2} \mathrm{O}$ and $\mathrm{FeSO}_{4} \cdot 7 \mathrm{H}_{2} \mathrm{O}$ solution was added dropwise into $\mathrm{NH}_{4} \mathrm{OH}$ solution and this product was termed as MMrco. For sonochemically method, the reaction between $\mathrm{Fe}^{3+} / \mathrm{Fe}^{2+}$ with $\mathrm{NH}_{4} \mathrm{OH}$ was done in ultrasonic batch (Branson 3210) and the aging time was $1 \mathrm{~h}$. The products are called UMco and UMrco. 


\section{Characterization of Materials}

The magnetites were first characterized for the functional groups by FT-IR. FT-IR spectra were recorded using a Shimadzu FTIR-820 IPC in the transmission mode in spectroscopic grade $\mathrm{KBr}$ pellets. XRD patterns of samples to study the crystalline structure were recorded using a Shimadzu XRD-6000 diffractometer with Ni-filtered $\mathrm{Cu} \mathrm{K \alpha}$ radiation $(\lambda=0.15406 \mathrm{~nm})$ at voltage $40 \mathrm{kV}$ and current 30 $\mathrm{mA}$. Every sample was scanned in steps of $0.02^{\circ}(2 \theta)$ in the range from $0^{\circ}$ to $70^{\circ}$ with a count time of $4 \mathrm{~s}$ per step. The magnetic properties of the as-synthesized nanopowder magnetites were analyzed by Vibrating Sample Magnetometer (VSM) tipe OXFORD VSM 1.2H. The morphology of samples was viewed by scanning electron microscopy (SEM) using a JSM-6360 instrument.

\section{RESULT AND DISCUSSION}

Synthesis of magnetite is done in two methods that is co-precipitation (co) and reverse co-precipitation (rco). Co-precipitation is the simplest method and the most economical and efficient way to get the magnetite particles. In ordinary co-precipitation, a solution of $\mathrm{Fe}^{2+} / \mathrm{Fe}^{3+}$ was titrated using an alkaline solution $3,5 \mathrm{~N} \mathrm{NH}_{4} \mathrm{OH}$ to $\mathrm{pH} 11$, while on the reverse-co-precipitation method, $\mathrm{NH}_{4} \mathrm{OH}$ solution was titrated using a mixed solution of $\mathrm{Fe}^{2+} / \mathrm{Fe}^{3+}$. Both methods were done mechanically and sonochemically. The mechanic treatment was done using a magnetic stirrer barr and hot plate stirrer, while the sonochemical treatment was performed in an ultrasonic batch. Instead of $\mathrm{NaOH}$, $\mathrm{NH}_{4} \mathrm{OH}$ solution was employed in this study as precipitating agent in order to obtain magnetite with better crystallinity and smaller size [14]. The formation of magnetite began to form at $\mathrm{pH} 9$ and as predicted from the Pourbaix diagram [9] the formation of magnetite would be complete at $\mathrm{pH} 11$. According to Pourbaix diagram, $\mathrm{Fe}_{3} \mathrm{O}_{4}$ precipitates as a stable phase in highly basic aqueous media where the precipitated $\mathrm{Fe}_{3} \mathrm{O}_{4}$ nanoparticles acquire negative charges on their surface. The co-precipation reaction is represented by eq.:

$$
\begin{gathered}
\mathrm{Fe}^{2+}+2 \mathrm{OH}^{-} \rightarrow \mathrm{Fe}(\mathrm{OH})_{2} \\
\mathrm{Fe}^{3+}+3 \mathrm{OH}^{-} \rightarrow \mathrm{Fe}(\mathrm{OH})_{3} \\
\mathrm{Fe}(\mathrm{OH})_{2}+2 \mathrm{Fe}(\mathrm{OH})_{3} \rightarrow \mathrm{Fe}_{3} \mathrm{O}_{4}+4 \mathrm{H}_{2} \mathrm{O}
\end{gathered}
$$

\section{A. Characterization by FTIR}

FTIR characterization results for the mechanically and sonochemically assisted co-precipitation and reverse co-precipitation methods yield clear absorption bands at wavelengths of 586 and $524 \mathrm{~cm}^{-1}$ which show the vibration of strain Fe-O tetrahedral and 393; 378; 339; $354 \mathrm{~cm}^{-1}$ which correspond to strain of Fe-O octahedral of $\mathrm{Fe}_{3} \mathrm{O}_{4}$ (Fig. 1(A)). In addition, there are a weak absorption bands at wave number 1627, 1635 and around $3400 \mathrm{~cm}^{-1}$ which are the stretching vibration of $\mathrm{OH}$ groups on the surface of the magnetite indicating that the crystallization process was complete [16], [8]. But with the obvious appear of -OH groups on UMco shows that $\mathrm{Fe}(\mathrm{OH})_{2}, \mathrm{Fe}(\mathrm{OH})_{3}$ and $\mathrm{FeOOH}$ formed as a result of hydrolisation on the surface of $\mathrm{Fe}_{3} \mathrm{O}_{4}$ [12].

\section{B. Characterization by XRD}

Structures of magnetite crystal were characterized using XRD. Diffractogram XRD magnetite synthesis results shown in Fig. 1B. The resulted diffractogram shows six peaks corresponding to the standard data for $\mathrm{Fe}_{3} \mathrm{O}_{4}$ (JCPDS no. 89.0691). The characteristic diffraction peaks of the synthesized magnetites seen in $2 \theta=30.27^{\circ}, 35.68^{\circ}, 43.30^{\circ}$, $57.21^{\circ}, 62.90^{\circ}$ and $74.51^{\circ}$ which are the reflection (220), (311), (400), (511), (440) and (533). Diffractogram peaks at d311 $\left(2 \theta=35.68^{\circ}\right)$ which were high and sharp observed on magnetite synthesized by co-precipitation. This indicates a higher crystallinity of magnetite synthesized by co-precipitation method rather than reverse-co-precipitation. Based on the XRD data, the size of the magnetite crystals can be estimated using the Debye-Scherrer equation [15]:

$$
d=\frac{K \lambda}{\beta \cos \theta}
$$

where $d$ is the crystal size (nm), $K$ is a constant Sherrer (0.89), $\lambda$ is the wavelength of X-rays $(0.15418 \mathrm{~nm}), \beta$ is the peak FWHM (Full Width at a Half Maximum) the strongest peak (d311) (radians), $\theta$ is the Bragg diffraction angle (radians). The average size distribution of magnetite crystals synthesized by the Debye-Sherrer equation presented in Table I.

In addition to 6 peaks corresponding to the peaks of magnetite, there is one peak in $2 \theta=32^{\circ}$ which is the peak of $\varepsilon-\mathrm{Fe}_{2} \mathrm{O}_{3}$ [17]. This shows that the synthesized magnetite do not have high purity because synthesis conditions not under $\mathrm{N}_{2}$ gas. In highly alkaline media, Pourbaix diagram indicates that other phases such as $\mathrm{FeO}_{4}{ }^{2-}, \mathrm{Fe}_{2} \mathrm{O}_{3}, \mathrm{Fe}(\mathrm{OH})_{3}$ and $\mathrm{HFeO}_{2}{ }^{-}$are possible to form in this condition. In addition, magnetite can be seen as a combination of $\mathrm{FeO}$ and $\mathrm{Fe}_{2} \mathrm{O}_{3}$. When synthesized not under conditions of $\mathrm{N}_{2}$ gas, $\mathrm{FeO}$ can be oxidized to $\mathrm{Fe}_{2} \mathrm{O}_{3}$ or $\mathrm{Fe}(\mathrm{OH})_{3}$ according to the following reaction equation [9]:

$$
\begin{gathered}
\text { 2(FeO. } \left.\mathrm{Fe}_{2} \mathrm{O}_{3}\right)+\frac{1}{2} \mathrm{O}_{2} \rightarrow 3 \mathrm{Fe}_{2} \mathrm{O}_{3} \\
\mathrm{Fe}_{3} \mathrm{O}_{4}+\frac{1}{4} \mathrm{O}_{2}+4 \frac{1}{2} \mathrm{H}_{2} \mathrm{O} \rightarrow 3 \mathrm{Fe}(\mathrm{OH})_{3}
\end{gathered}
$$

That oxidation reaction explain why synthesis of magnetite in alkaline media in air has been always abandoned to avoid the formation of phase-impure $\mathrm{Fe}_{3} \mathrm{O}_{4}$.

TABLE I: The Average Size Distribution of MAgnetite Crystals SYNTHESIZED

\begin{tabular}{lcccc}
\hline \hline sample & $2 \theta$ (degree) & $\theta$ (radian) & $\begin{array}{c}\text { FWHM }(\beta) \\
\text { (radian) }\end{array}$ & $\begin{array}{c}\text { Crystal size } \\
\text { average }(\mathrm{nm})\end{array}$ \\
\hline MMco & 35.56 & 0.310 & 0.01112 & 15.6 \\
UMco & 35.70 & 0.316 & 0.01044 & 14.6 \\
MMrco & 35.68 & 0.311 & 0.01142 & 13.3 \\
UMrco & 35.53 & 0.311 & 0.01394 & 10.9 \\
\hline \hline
\end{tabular}

Based on calculation results (Table I), the crystal size of the magnetite which synthesized by reverse co-precipitation method smaller than that by the ordinary co-precipitation. In addition, magnetites synthesized by sonochemical treatment have crystal sizes smaller than using mechanical treatment. However, based on the high and sharp peaks in the XRD pattern, it is seen that crystallinity of particles synthesized by co-precipitation higher than that reverse co-precipitation (Fig. 1). 

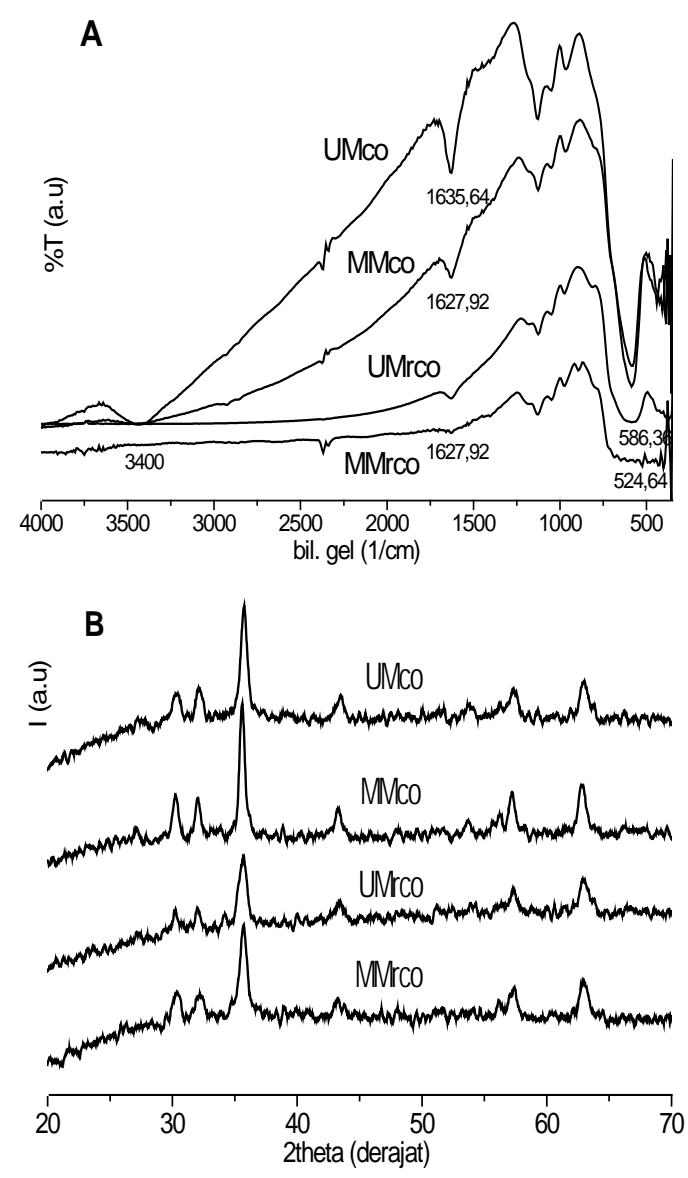

Fig. 1. FTIR spectra (A) and XRD patterns (B) of the magnetite.

\section{Magnetic Properties}

Magnetic properties were measured at room temperature using a VSM (Fig. 2). The results of measurements of the specific saturation magnetization $\left(M_{s}\right)$ of the two samples of magnetite, MMco and UMco, yielded the value $M_{s}$ of UMco (73.6 emu/g) that was higher than MMco (65.2 emu/g). This is likely due to a more homogeneous particle UMco and purity higher than MMco. So although UMco give smaller particle size, but it produces higher magnetic properties than MMco. This result can be explained by their agglomeration and size characteristics. Previous result by Thapa et al. [18] attributed the increase in the magnetization of magnetite with the decerase of particle size to the decrease in the oxygen content in the magnetite samples and the subsequent increase of $\left[\mathrm{Fe}^{2+}\right]$ in the magnetite lattice, which is the main cause of magnetic character of magnetite nanoparticles. Ma and Liu [19] related the decrease in magnetic properties with increasing size of $\mathrm{Fe}_{3} \mathrm{O}_{4}$ nanoparticles to the agglomeration of particles, which is caused by the hydrophobic interaction between them.

\section{Morfology of Magnetite}

Fig. 3 gives the SEM image of the prepared magnetite via co-precipitation method. Based on SEM micrographs (Fig. 3(a) and 3(b)) it seen that the morphology of magnetites is spherical and agglomerated with homogeneous size distribution. The magnetite which was synthesized sonochemically showed smaller particle size than mechanically synthesized magnetite. It is proved that the sonochemical method can reduce the size of the magnetite particles. Ultrasound irradiation may locally produce extremely-high temperatures $(>5000 \mathrm{~K})$ and pressures $(>20$ $\mathrm{MPa}$ ) during acoustic cavitation, providing enough energy for generation of crystal nuclei. This is favorable to significantly accelerating the nucleation of magnetite particles [15]. Agglomeration formed by hydrophobic interactions between nanoparticles of magnetite nanoparticles.

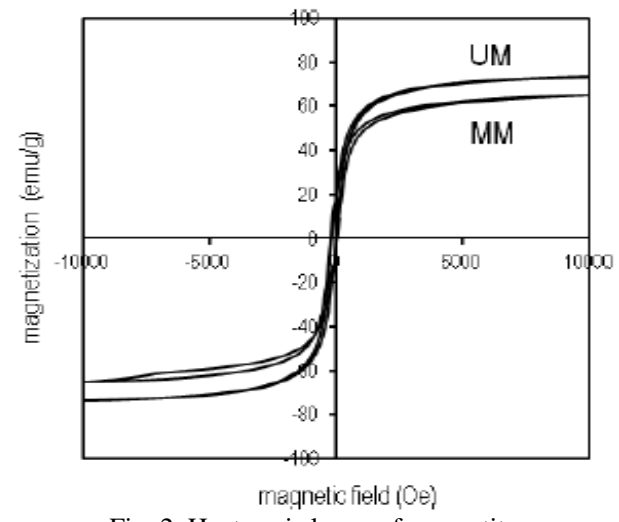

Fig. 2. Hysteresis loops of magnetite.
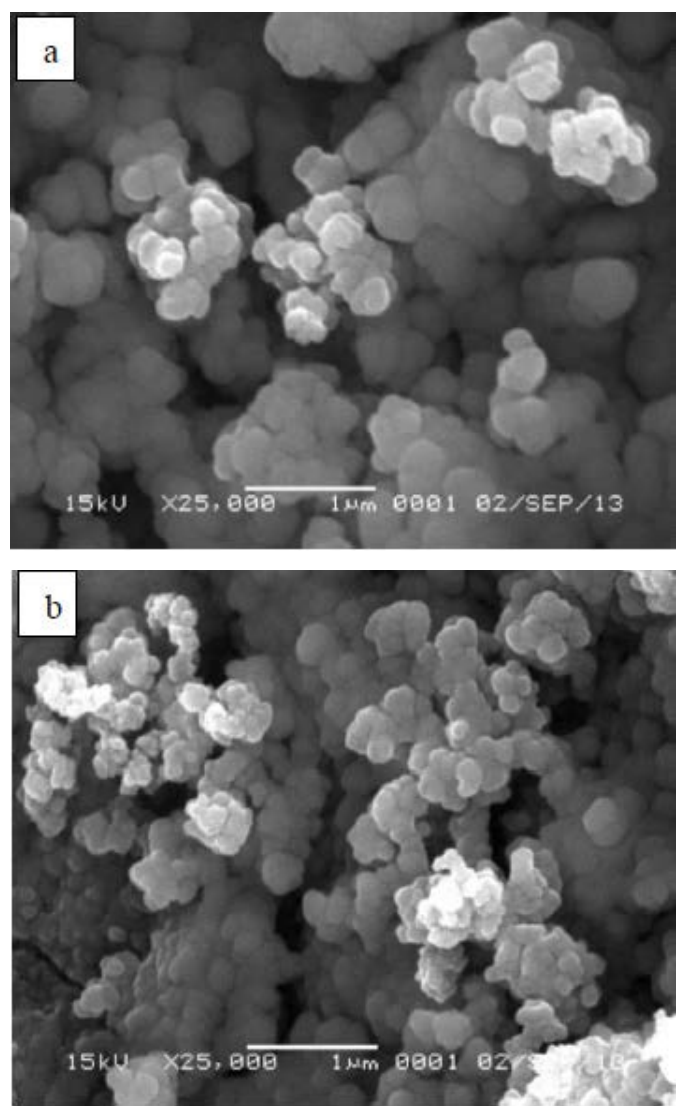

Fig. 3. SEM image of (a) the mechanically and (b) sonochemically magnetite.

\section{CONCLUSION}

Magnetite could be synthesized by mechanically or sonochemically assisted co-precipitation and reverse co-precipitation methods. This both methods yielded magnetite particles with small and homogenous size but magnetites synthesized by sonochemical treatment have crystal sizes smaller than using mechanical treatment. In this study, the magnetite was synthesized with no protecting gas $\mathrm{N}_{2}$ and could be easily done.

\section{ACKNOWLEDGMENT}

The authors would like to thank Directorate General of 
Higher Education (DGHE), Department of National Education Republic Indonesia for providing the financial support.

\section{REFERENCES}

[1] A. S. Teja and P. Y. Koh, "Synthesis, properties, and applications of magnetic iron oxide nanoparticles,” Progress in Crystal Growth and Characterization of Materials, no. 55, pp. 22-45, 2009.

[2] J. Yang, S. B. Park, H. G. Yoon, Y. M. Huh, and S. Haam, "Preparation of poly $\varepsilon$-caprolactone nanoparticles containing magnetite for magnetic drug carrier,” International Journal of Pharmaceutics, no. 324, pp. 185-190, 2006.

[3] L. Zhou, J. Yuan, W. Yuan, X. Sui, S. Wu, Z. Li, and D. Shen, "Synthesis, characterization, and controllable drug release of pH-sensitive hybrid magnetic nanoparticles,” Journal of Magnetism and Magnetic Materials, no. 321, pp. 2799-2804, 2009.

[4] F. X. Hu, K. G. Neoh, and E. T. Kang, "Synthesis and in vitro anti-cancer evaluation of tamoxifen-loaded magnetite/PLLA composite nanoparticles,” Biomaterials, no. 27, pp. 5725-5733, 2006.

[5] S. B. Brijmohan and M. T. Shaw, "Magnetic ion-exchange nanoparticles and their application in proton exchange membranes," Journal of Membrane Science, no. 303, pp. 64-71, 2007.

[6] Y. F. Shen, J. Tang, Z. H. Nie, Y. D. Wang, Y. Ren, and L. Zuo, "Preparation and application of magnetic $\mathrm{Fe}_{3} \mathrm{O}_{4}$ nanoparticles for wastewater purification,” Separation and Purification Technology, no. 68, pp. 312-319, 2009.

[7] Y. C. Chang, S. W. Chang, and D. H. Chen, "Magnetic chitosan nanoparticles: Studies on chitosan binding and adsorption of $\mathrm{Co}(\mathrm{II})$ ions,” Reactive \& Functional Polymers, vol. 66, no. 3, pp. 335-341, 2006.

[8] J. Meng, G. Yang, L. Yan, and X. Wang, "Synthesis and characterization of magnetic nanometer pigment $\mathrm{Fe}_{3} \mathrm{O}_{4}$," Dyes and Pigments, no. 66, pp. 109-113, 2005.

[9] R. El-kharrag, A. Amin, and Y. E. Greish, "Low temperature synthesis of monolithic mesoporous magnetite nanoparticles," Ceramics International, no. 38, pp. 627-634, 2012.

[10] H. Yan, J. Zhang, C. You, Z. Song, B. Yu, and Y. Shen, "Influences of different synthesis conditions on properties of $\mathrm{Fe}_{3} \mathrm{O}_{4}$ nanoparticles," Materials Chemistry and Physics, no. 113, pp. 46-52, 2009.

[11] D. Hu, Y. Wang, and Q. Song, "Weakly magnetic field-assisted synthesis of magnetite nano-particles in oxidative co-precipitation," Particuology, no. 7, pp. 363-367, 2009.
[12] W. Lu, Y. Shen, A. Xie, and W. Zhang, "Green synthesis and characterization of superparamagnetic $\mathrm{Fe}_{3} \mathrm{O}_{4}$ nanoparticles,” Journa of Magnetism and Magnetic Materials, no. 322, pp. 1828-1833, 2010.

[13] Â. L. Andrade et al., "pH effect on the synthesis of magnetite nanoparticles by the chemical reduction-precipitation method," Quim. Nova., vol. 33, no. 3, pp. 524-527, 2010.

[14] N. Wang, L. Zhu, D. Wang, M. Wang, Z. Lin, and H. Tang, "Sono-assisted preparation of highly-efficient peroxidase-like $\mathrm{Fe}_{3} \mathrm{O}_{4}$ magnetic nanoparticles for catalytic removal of organic pollutants with $\mathrm{H}_{2} \mathrm{O}_{2}$," Ultrasonics Sonochemistry, no. 17, pp. 526-533, 2010.

[15] T. Sulistyaningsih, D. S. V. Silalahi, S. J. Santosa, D. Siswanta, and B. Rusdiarso, "Synthesis and characterization of Magnetic MgAl-NO $\mathrm{N}_{3}$-HT composite via the chemical co-precipitation method," in Proc. Chemical, Biological and Environmental Engineering, 2013 vol. 58, pp. 95-99.

[16] K. Petcharoen and A. Sirivat, "Synthesis and characterization of magnetite nanoparticles via the chemical co-precipitation method," Materials Science and Engineering B, no. 177, pp. 421- 427, 2012.

[17] D. Maity and D. C. Agrawal, "Synthesis of iron oxide nanoparticles under oxidizing environment and their stabilization in aqueous and non-aqueous media," Journal of Magnetism and Magnetic Materials, no. 308, pp. 46-55, 2007.

[18] D. Thapa, V. R. Palkar, M. B. Kurup, and S K. Malik, "Properties of magnetite nanoparticles synthesized through a novel chemical route," Journal of Materials Letter, no. 58, pp. 2692-2694, 2004.

[19] Z. Ma and H. Liu, "Synthesis and surface modification of magnetic particles for application in biotecnology and biomedicine,” Journal China Particuology, no. 5, pp. 1-10, 2007.

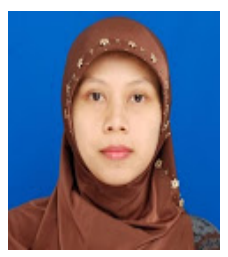

Triastuti Sulistyaningsih was born in Yogyakarta, Indonesia on April 11, 1977. She received her master's degree in environmental chemistry from the Universitas Gadjah Mada, Indonesia. At present, she is doing her $\mathrm{PhD}$ in the Department of Chemistry, Faculty of Mathematics and Natural Sciences, Universitas Gadjah Mada under the supervision of Prof/Dr. Sri Juari Santosa, M.Eng., Dr. Dwi Siswanta, and Prof/Dr. Bambang Rusdiarso, DEA. Her area of interest is magnetite-hydrotalcite material. She works at the Department of Chemistry, Faculty of Mathematics and Natural Sciences, Semarang State University, Semarang, Indonesia. 